\title{
Region-specific tauopathy and synucleinopathy in brain of the alpha-synuclein overexpressing mouse model of Parkinson's disease
}

\author{
Tiffany Kaul', Joel Credle', Thomas Haggerty ${ }^{1}$, Adam W Oaks', Eliezer Masliah² and Anita Sidhu*
}

\begin{abstract}
Background: $\alpha$-synuclein $[\alpha-S y n]$-mediated activation of GSK-3 $\beta$ leading to increases in hyperphosphorylated Tau has been shown by us to occur in striata of Parkinson's diseased [PD] patients and in animal models of PD. In Alzheimer's disease, tauopathy exists in several brain regions; however, the pattern of distribution of tauopathy in other brain regions of PD or in animal models of PD is not known. The current studies were undertaken to analyze the distribution of tauopathy in different brain regions in a widely used mouse model of PD, the $\alpha$-Syn overexpressing mouse.

Results: High levels of $\alpha$-Syn levels were seen in the brain stem, with a much smaller increase in the frontal cortex; neither cerebellum nor hippocampus showed any overexpression of $\alpha$-Syn. Elevated levels of p-Tau, hyperphosphorylated at Ser202, Ser262 and Ser396/404, were seen in brain stem, with lower levels seen in hippocampus. In both frontal cortex and cerebellum, increases were seen only in p-Ser396/404 Tau, but not in pSer202 and p-Ser262. p-GSK-3 $\beta$ levels were not elevated in any of the brain regions, although total GSK-3 $\beta$ was elevated in brain stem. p-p38MAPK levels were unchanged in all brain regions examined, while p-ERK levels were elevated in brain stem, hippocampus and cerebellum, but not the frontal cortex. p-JNK levels were increased in brain stem and cerebellum but not in the frontal cortex or hippocampus. Elevated levels of free tubulin, indicating microtubule destabilization, were seen only in the brain stem.

Conclusion: Our combined data suggest that in this animal model of PD, tauopathy, along with microtubule destabilization, exists primarily in the brain stem and striatum, which are also the two major brain regions known to express high levels of $\alpha$-Syn and undergo the highest levels of degeneration in human PD. Thus, tauopathy in PD may have a very restricted pattern of distribution.
\end{abstract}

\section{Background}

$\alpha$-Synuclein $(\alpha-S y n)$ is a presynaptic, ubiquitously expressed protein in the brain, whose chief physiological function may be the regulation of synaptic levels of dopamine and other monoamines through modulation of the re-uptake function of monoamine transporters [1]. Overexpression of $\alpha$-Syn, through its gene duplication and triplication, is linked to idiopathic Parkinson's disease [2-6], while its A30P and A53T mutants cause the autosomal dominant forms of familial PD $[7,8]$. In pathological states, $\alpha$-Syn misfolds into aggregates and

\footnotetext{
* Correspondence: sidhua@georgetown.edu

'Department of Biochemistry and Molecular and Cell Biology, University of California San Diego, La Jolla, California

Full list of author information is available at the end of the article
}

accumulates into neuronal inclusion bodies, termed Lewy bodies (LBs), which are pathological hallmarks of PD and other synucleinopathies [9-12]. Post-mortem immunohistochemical studies show the presence of hyperphosphorylated Tau ( $\mathrm{p}-\mathrm{Tau}$ ), a protein normally linked to the genesis of Alzheimer's disease (AD), coexisting with $\alpha$-Syn aggregates in the same neurons in PD and other synucleinopathies [13-20]. Conversely, in tauopathies such as AD, elevated levels of $\alpha$-Syn have been found [21-26], along with LBs [21,27,28].

More recently, we have shown in the MPTP/MPP in vivo and in vitro models of $\mathrm{PD}$, respectively, that increases in $\alpha$-Syn can initiate and sustain p-Tau formation with hyperphosphorylation at Ser202, Ser262 and Ser396/404, which are the same epitopes that are 
hyperphosphorylated in AD and lead to pathological changes [29-32]. In PD, there was an absolute requirement for the presence of $\alpha$-Syn in the induction of hyperphosphorylation of Tau, and in MPTP-treated $\alpha$ Syn-/- mice or toxin-treated neuronal cells lacking $\alpha$ Syn we failed to observe any p-Tau formation [29,31], suggesting that $\alpha$-Syn is central to tauopathy. In addition, we also found increases in levels of active GSK-3 $\beta$ [p-GSK-3 $\beta$, hyperphosphorylated at Tyr216], a major kinase known to hyperphosphorylate Tau at the above mentioned sites. Blockade of this kinase with inhibitors prevent $\alpha$-Syn-mediated $p$-Tau formation $[29,31,32]$, thereby implicating $\mathrm{p}-\mathrm{GSK}-3 \beta$ in the mechanistic actions of $\alpha$-Syn.

More recently, we found tauopathy in striatum of both the $\alpha$-Syn overexpressing and the $\alpha$-Syn A53T mutant mouse models of PD [33,34]. In both studies, we found Tau hyperphosphorylated at Ser202, Ser262 and Ser396/ 404 , which was accompanied by elevated levels of $\alpha$-Syn and $\mathrm{p}-\mathrm{GSK}-3 \beta$. Interestingly, changes in $\mathrm{p}$-Tau levels, which bind to and stabilize microtubules, lead to destabilization of the microtubule and actin networks in the striatum [33], indicating that $\mathrm{p}$-Tau formation increased pathology in this brain region.

That tauopathy occurs in humans was confirmed using postmortem striata from PD patients, where elevated levels of $\alpha$-Syn, $\mathrm{p}$-Tau and $\mathrm{p}$-GSK-3 $\beta$ were noted [35]. Interestingly, such changes were seen only in the striatum, but not in the inferior frontal gyrus of PD patients, where, although increased levels of $\alpha$-Syn were noted, no changes in levels of $\mathrm{p}$-Tau or $\mathrm{p}-\mathrm{GSK}-3 \beta$ were observed. This suggested that unlike AD, where tauopathy is seen throughout the brain, tauopathy in PD may be limited to dopaminergic neurons and have a more restricted pattern of distribution in the brain.

To further test this, the current studies were undertaken, whereby different brain regions of the $\alpha$-Syn overexpressing mouse model of PD [36] were analyzed for changes in $\alpha$-Syn, $\mathrm{p}$-Tau and Tau kinases; the brain regions analyzed were brain stem, hippocampus, frontal cortex and cerebellum. The data presented here show that high levels of tauopathy, along with increases in $\alpha$ Syn, are observed in brain stem, followed by more modest changes in hippocampus. In other brain regions tested, increases were seen only in p-Ser396/404 Tau. These tauopathic changes were independent of p-GSK$3 \beta$ and appeared to be mediated by $\mathrm{p}$-JNK and/or $\mathrm{p}$-ERK.

\section{Results}

Expression levels of $\alpha$-Syn in different brain regions of the PDGF- $\alpha$-Syn overexpressing mice

We have previously [33] shown that $\alpha$-Syn levels are significantly $[p<0.05$ ] elevated [by $113 \%$ compared to litter-mate non-transgenic mice] in striata of PDGF- $\alpha$ Syn overexpressing mice and that such changes were accompanied by profound tauopathy and increased levels of p-GSK-3 $\beta$, the kinase known to hyperphosphorylate Tau at distinct epitopes. Increased levels of $\alpha$-Syn were similarly observed in postmortem striata of PD and PD with dementia [35].

To assess whether $\alpha$-Syn levels were also increased in other brain regions of these transgenic mice, we examined brain stem, hippocampus, frontal cortex and cerebellum [Figure 1]. The highest levels of $\alpha$-Syn were
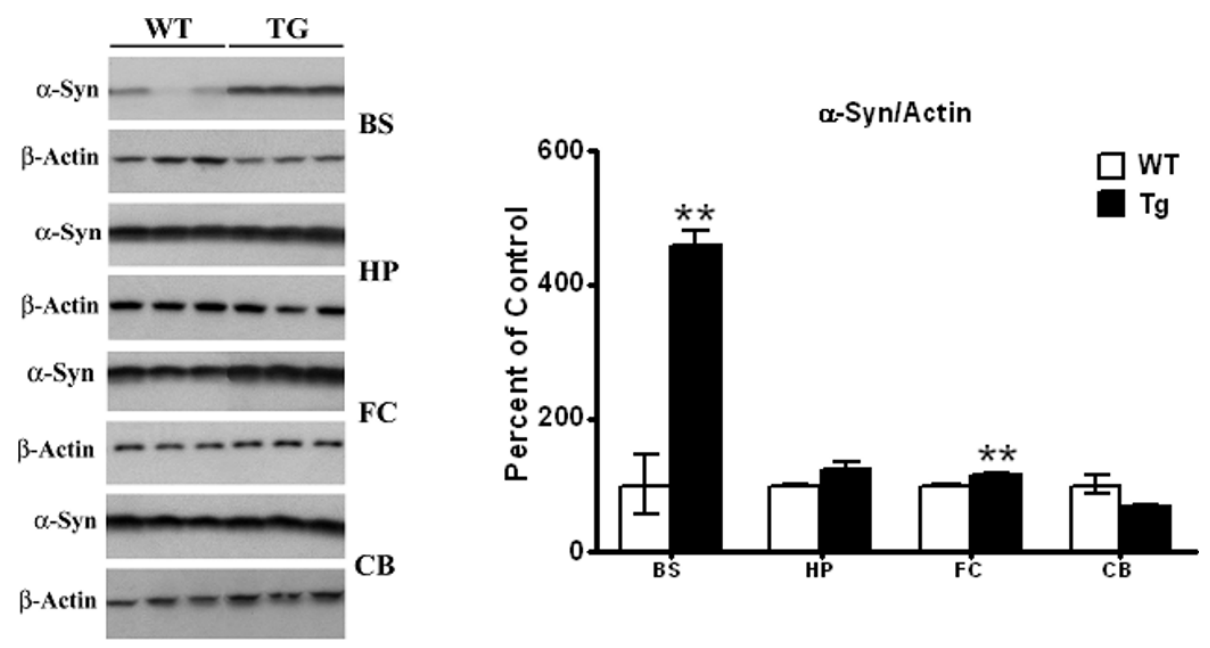

Figure 1 Western blots of $\alpha$-Syn levels in brain stem, hippocampus, frontal cortex, and cerebellum of PDGF- $\alpha$-Syn overexpressing transgenic mice. Brain stem [BS], hippocampus HP], frontal cortex [FC] and cerebellum [CVB] from PDGF- $\alpha$-Syn transgenic mice and litter-mate non-transgenic mice [WT] were solubilized in RIPA buffer and analyzed by Western blots for $\alpha$-Syn levels. $\alpha$-Syn was normalized to $\beta$-actin. All values are expressed as percent change relative to changes observed in WT control animals. Results are from 3-4 animals per group; $\left.{ }^{*}, p<0.05\right]$ and [**, $p<0.01$ ] compared to corresponding brain regions in WT animals. All blots are representative of samples. 
observed in brain stem, where $[p<0.01]$ increases of $358 \%$ were noted. The brain stem is to undergo neurodegenerative changes in Parkinson's disease [37], and such large increases in $\alpha$-Syn levels in this region may parallel the pathological changes occurring in humans. More modest increases in $\alpha$-Syn levels in hippocampus and frontal cortex were also noted, but they were significant only for the frontal cortex [15\%, $p<0.01]$. In the cerebellum, a small insignificant decrease of $\sim 30 \%$ in $\alpha$ Syn expression was seen [Figure 1].

\section{Tauopathic changes in different brain regions of the PDGF- $\alpha$-Syn overexpressing mice}

In striata of the PDGF- $\alpha$-Syn overexpressing mouse [33] as well as in striata of postmortem PD brains [35], high levels of tauopathy were previously detected where increases in p-Tau hyperphosphorylated at Ser202, Ser262 and Ser396/404 were observed. In the current study, the highest levels of tauopathy were seen in brain stem of the PDGF- $\alpha$-Syn mice, followed by more modest tauopathic changes in other brain regions [Figure 2]. Thus, in the brain stem [Figure 2A], p-Ser202 levels of Tau were significantly $[p<0.05]$ increased by $73 \%$, whereas p-Ser396/404 levels were elevated by $43 \%$, compared to litter-mate nontransgenic mice. These increases in p-Ser202 are lower than those seen previously in the striatum [205\% increase] of the transgenic mice, and the increases in p-Ser396/ 404 are also lower than those seen previously in striata, where we had observed a 50-fold (5000\%) increase [33]. For p-Ser262, however, we observed a 25 -fold (2500\%) increase in brain stem, which was much higher than the $255 \%$ increase we had previously seen in the striatum [33].

In hippocampus [Figure 2B], significant increases were seen for all three epitopes of p-Tau, and although the levels of increases in p-Ser262 were much lower than those seen in brain stem, p-Ser202 and p-Ser396/404 were higher than in brain stem. Thus, increases of 158 $[p<0.05], 56[p<0.01]$ and 592\% $[p<0.01]$ were seen for $\mathrm{p}$-Ser202, p-Ser262 and p-Ser396/404, respectively, in hippocampus.

In frontal cortex [Figure 2C], no changes were seen for either p-Ser202 or p-Ser262, while p-Ser396/404 was significantly $[p<0.01]$ increased by $425 \%$. Similarly in the cerebellum, we failed to observed changes in $\mathrm{p}$ Ser202 and p-Ser262, while significant $[p<0.05]$ increases of $299 \%$ were noted for p-Ser396/404. Together, these data indicate that the tauopathy observed in the various brain regions has the following rank order of intensity: brain stem > hippocampus > frontal cortex $>$ cerebellum.

\section{Immunohistochemical analysis of $\alpha$-Syn and $p$-Tau}

Staining was performed on brain slices and the following brain regions were examined: striatum, frontal cortex, cerebellum and brain stem, using antibodies against $\alpha$-Syn [Figure 3A] or p-Ser396/404 Tau [Figure 3B]. As was shown in the Western blots [Figure 1 \&2], both $\alpha$ Syn and p-Tau stain more intensely in the Tg mouse brains than wild type. In Figure 3A, white arrows indicate large cellular bodies staining positively for $\alpha$-Syn in the Tg versus WT specific brain regions. A similar pattern of staining was seen for the specific brain regions stained for p-Ser396/404 Tau (Figure 3B) where white arrows indicate the presence of large cellular bodies seen in the Tg but not the WT brain sections. Moreover, the highlighted bodies shown in the inset pictures are reminiscent of the Lewy bodies commonly seen in Parkinson's disease brains.

\section{Tau kinases in different brain regions of the PDGF- $\alpha$-Syn overexpressing mice}

Tau is hyperphosphorylated by several kinases including p-GSK-3 $\beta$, p-JNK, p-p38MAPK, p-ERK, cdk5, calmodulin kinase and protein kinase A [38]. Of these, we have previously found that $\mathrm{p}-\mathrm{GSK}-3 \beta$ was specifically activated by $\alpha$-Syn in vitro in MPP+-treated SH-SY5Y cells and mesencephalic primary neurons $[31,29]$ and in vivo in striata of MPTP-treated mice [32]. Moreover, blockade of p-GSK-3 $\beta$ with selective inhibitors or with lithium [31,32] abrogated GSK-3 $\beta$ activation and Tau hyperphosphorylation, suggesting a central role for this kinase in $\alpha$-Syn-mediated $\mathrm{p}$-Tau formation in dopaminergic cells and neurons.

In the present study, we examined activated p-GSK$3 \beta$ levels [hyperphosphorylated at tyrosine 216] in the different brain regions. The antibody we used recognizes both the $\alpha$-p-GSK-3 $\beta$ [upper band] and the $\beta$-pGSK-3 $\beta$ band of the kinase. Therefore, in all studies, only the lower band was used in all calculations. In striata, we had previously found p-GSK-3 $\beta$ levels were significantly increased [by $112 \%, p<0.05$ ] in the PDGF- $\alpha$-Syn transgenic mice [33]. In brain stem [Figure $4 \mathrm{~A}$ ], we failed to observe any increases in p-GSK$3 \beta$ levels and instead found that p-GSK-3 $\beta$ was significantly $[p<0.01]$ decreased by $70 \%$. The decrease was due to an overall increase in total GSK-3 $\beta$ levels [see Figure 4A], so that when p-GSK-3 $\beta$ levels were computed according to total GSK-3 $\beta$ levels, an overall net decrease was seen. This was accompanied by increases in levels of the inactive form of GSK-3 $\beta$, phosphorylated at Ser9, which leads to inactivation of GSK-3 $\beta$ [data not shown]. In hippocampus [Figure $4 \mathrm{~A}]$, no significant changes in $\mathrm{p}-\mathrm{GSK}-3 \beta$ or total 
A.

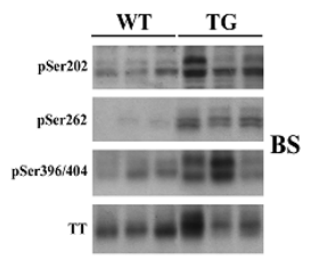

B.

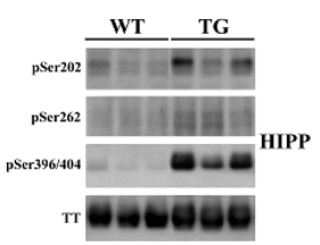

C.

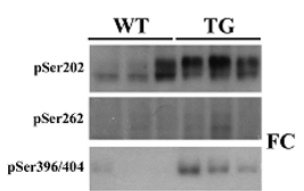

тт

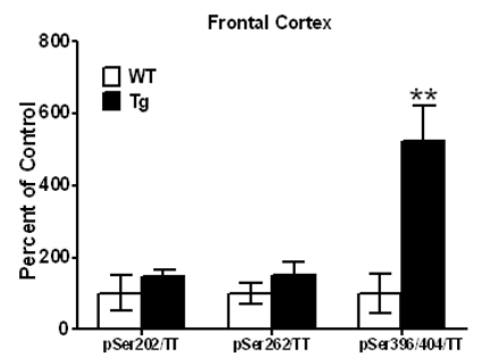

D
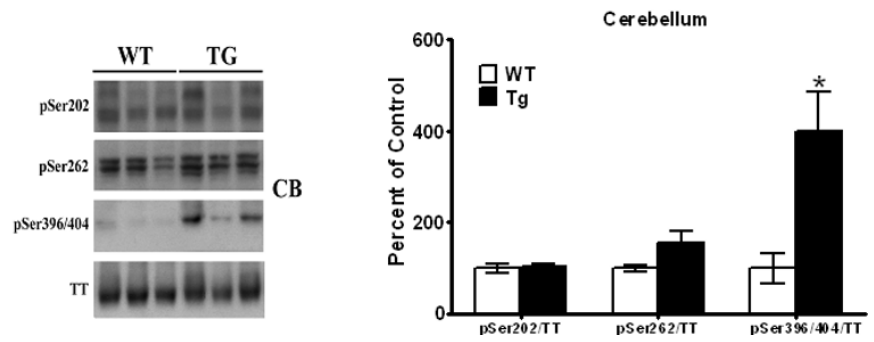

Figure 2 Western blots of $\mathrm{p}$-Tau levels in brain stem, hippocampus, frontal cortex, and cerebellum of PDGF- $\alpha$-Syn overexpressing transgenic mice. Brain stem, BS $[A]$, hippocampus, HP [B], frontal cortex, FC [C] and cerebellum, CB $[D]$ from PDGF- $\alpha$-Syn transgenic mice and litter-mate non-transgenic mice [WT] were solubilized in RIPA buffer and analyzed by Western blots for p-Tau levels. The following p-Taus were normalized to total Tau: p-Ser202, p-Ser262, and p-Ser396/404. All values are expressed as percent change relative to changes observed in WT control animals. Results are from 3-4 animals per group; $[*, p<0.05]$ and $[* *, p<0.01]$ compared to corresponding protein levels in WT animals. All blots are representative of samples. 
GSK-3 $\beta$ were found compared to litter-mate nontransgenic mice. Similarly, we also found no changes in $\mathrm{p}-\mathrm{GSK}-3 \beta$ levels in either frontal cortex or in cerebellum [Figure 4A]. These combined data suggest that unlike our findings in striata [33], where p-GSK-3 $\beta$ was found to hyperphosphorylate Tau, in other brain regions of the PDGF- $\alpha$-Syn mouse, $p-G S K-3 \beta$ did not participate in $\mathrm{p}$-Tau formation and was not activated by $\alpha$-Syn.

We therefore tested other kinases, by focusing on the mitogen-activated protein [MAP] family of kinases. In all brain regions, we failed to see any activation of $\mathrm{p}$ p38MAPK [Figure 4B], eliminating a role for this kinase in hyperphosphorylation of Tau; we were unable to detect this protein in the brain stem, even in nontransgenic mice. When p-ERK levels were examined, significant and robust increases in the levels of this enzyme were seen in brain stem [114\%, $p<0.01$ ], hippocampus [407\%, $p<0.05$ ] and frontal cortex [34\%, $p<0.05$ ], with no changes in the cerebellum. These data suggest that in other brain regions, p-ERK may play an essential role in the hyperphosphorylation of Tau.

When p-JNK levels were examined [Figure 4D], large increases in this kinase were seen in brain stem [874\%, $p<0.01$, with nonsignificant changes seen in the hippocampus [32\%] and frontal cortex [180\%]. Small but significant increases were also seen in the cerebellum [64\%, $p<0.05]$. These data suggest that in the brain stem, Tau may be hyperphosphorylated by both p-JNK and pERK, while in hippocampus and frontal cortex tauopathy may proceed entirely through p-ERK, but not through $\mathrm{p}-\mathrm{JNK}$, activation. In cerebellum, tauopathic changes may be mediated entirely through the action of p-JNK, but not p-ERK.

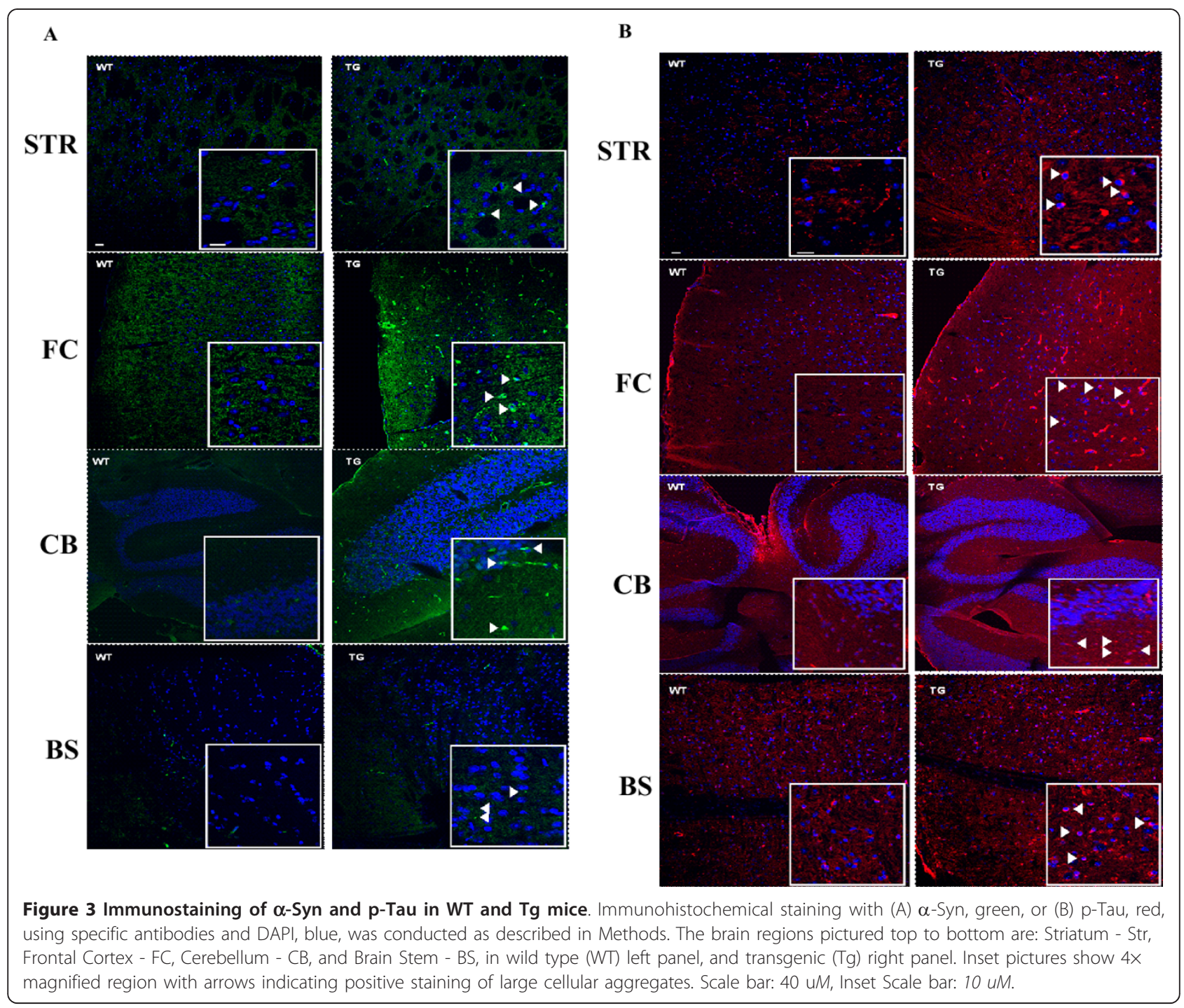


A.

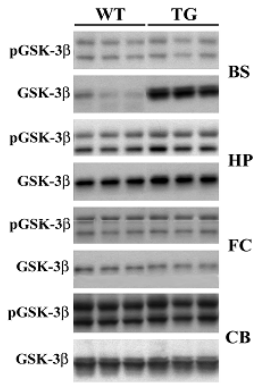

B.

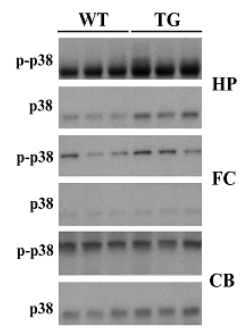

C.

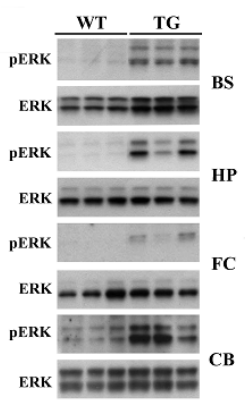

D.

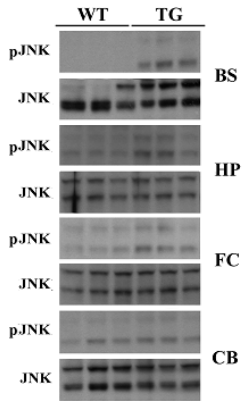

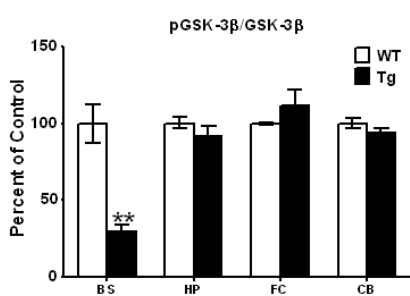
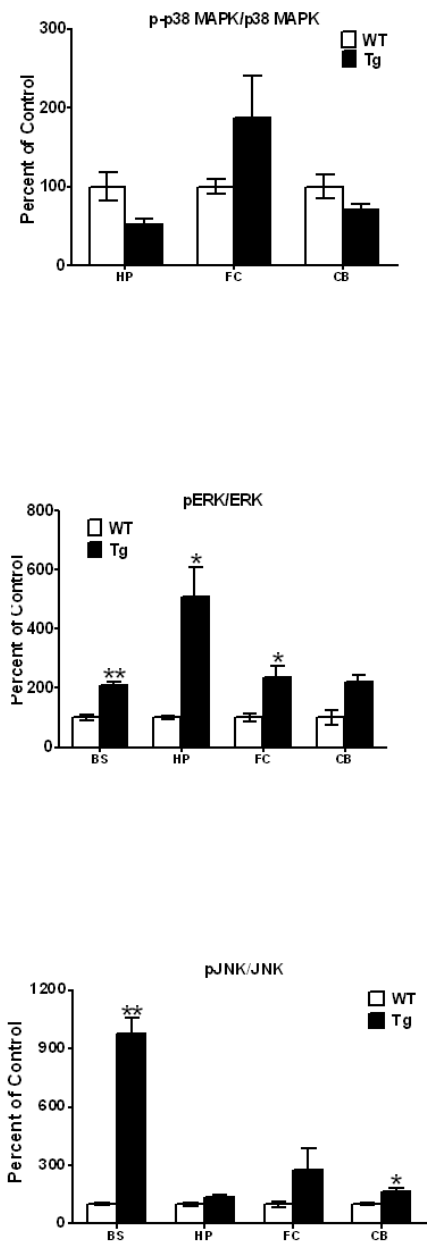

Figure 4 Western blots of p-GSK-3 $\beta$, p-p38, p-ERK, and p-JNK levels in brain stem, hippocampus, frontal cortex, and cerebellum of PDGF- $\alpha$-Syn overexpressing transgenic mice. Brain stem [BS], hippocampus [HP], frontal cortex [FC], and cerebellum [CB] from PDGF- $\alpha-S y n$ transgenic mice and litter-mate non-transgenic mice [WT] were solubilized in RIPA buffer and analyzed by Western blots for p-GSK-3ß [A], p-p38

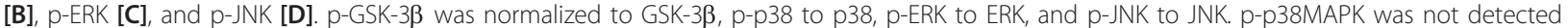
in brain stem and therefore this data is not shown. All values are expressed as percent change relative to changes observed in WT control animals. Results are from 3-4 animals per group; [*, $p<0.05]$ and [**, $p<0.01]$ compared to corresponding protein levels in WT animals. All blots are representative of samples. 
Elevated levels of free tubulin in brainstem of transgenic mice Hyperphosphorylation of Tau at Ser262 reduces its affinity for microtubules, causing it to dissociate from the microtubular network, leading to destabilization of the microtubules $[39,38]$. In striata of the PDGF- $\alpha-S y n$ overexpressing transgenic, we have previously shown a significant increase in soluble tubulin levels of $13 \%$, indicative of cytoskeleton remodeling in this brain region [33]. To test whether the tauopathy seen in the different brain regions of the transgenic mice also lead to microtubule remodeling, we measured levels of free tubulin in RIPA-soluble extracts [Figure 5]. In brain stem, we saw large and significant increases of $391 \%$ [ $p<0.01]$ in tubulin levels in transgenic mice, compared to wild type controls. In other brain regions, no significant changes in tubulin levels were noted between wild type and transgenic mice, except in frontal cortex, where a small but significant $[p<0.05]$ decrease of $13 \%$ was noted. The higher levels of soluble tubulin seen in the brain stem parallels the higher levels of p-Ser262 Tau seen in this brain region compared to other regions, and suggests profound remodeling of the microtubular cytoskeleton.

\section{Discussion}

We show here for the first time that an elevated state of tauopathy exists in the brain stem of the PDGF- $\alpha$-Syn overexpressing mice, where high levels of p-Ser202, pSer262 and p-Ser396/404. This was accompanied by lower levels of tauopathy in the hippocampus. In cerebellum and frontal cortex, increases were seen for only p-Ser396/404, but not for p-Ser202 or p-Ser262. The severity of tauopathy, in general, is linked to parallel increases in $\alpha$-Syn. Thus, in the brain stem, where we observed the most severe tauopathy, we also observed the highest increases in $\alpha$-Syn levels. By contrast, other brain regions that showed lower increases in $\alpha$-Syn levels were also characterized by lower levels of tauopathy. Our earlier studies have shown a tight linkage between $\alpha$-Syn and p-Tau levels, and we have shown a mandatory requirement for $\alpha$-Syn in tauopathy. Thus, in $\alpha$-Syn knock-out animals or in cells lacking $\alpha$-Syn [29], we fail to observe any tauopathic changes upon treatment with $\mathrm{PD}$-inducing neurotoxins. In $\mathrm{AD}$, it is long believed that the amyloid protein, $\beta$-amyloid, triggers the cascade of events that leads to generation of $\mathrm{p}$ Tau. Similarly in the context of PD, emerging evidence from our laboratory has identified $\alpha$-Syn to be the amyloid protein triggering tauopathy.

There have been only limited studies identifying the sites of hyperphosphorylation of Tau in PD brains. In one of these, Tau was found to be hyperphosphorylated at Ser396/404 in synaptic fractions from frontal cortex of PD postmortem striata [40]. Studies from our own laboratory have shown that Tau in striata of PD patients is hyperphosphorylated at Ser202, Ser262 and Ser396/ 404 , where increases of 23, 34 and $81 \%$ were observed in PD compared to control, non-diseased striata [35], testifying to the pathophysiological relevance of these sites. There are more than 45 sites of hyperphosphorylation of Tau identified in AD [38] and the molecular consequences of only a few of these sites are known. Tau is primarily located along axons and, in general, hyperphosphorylation of Tau reduces its affinity for

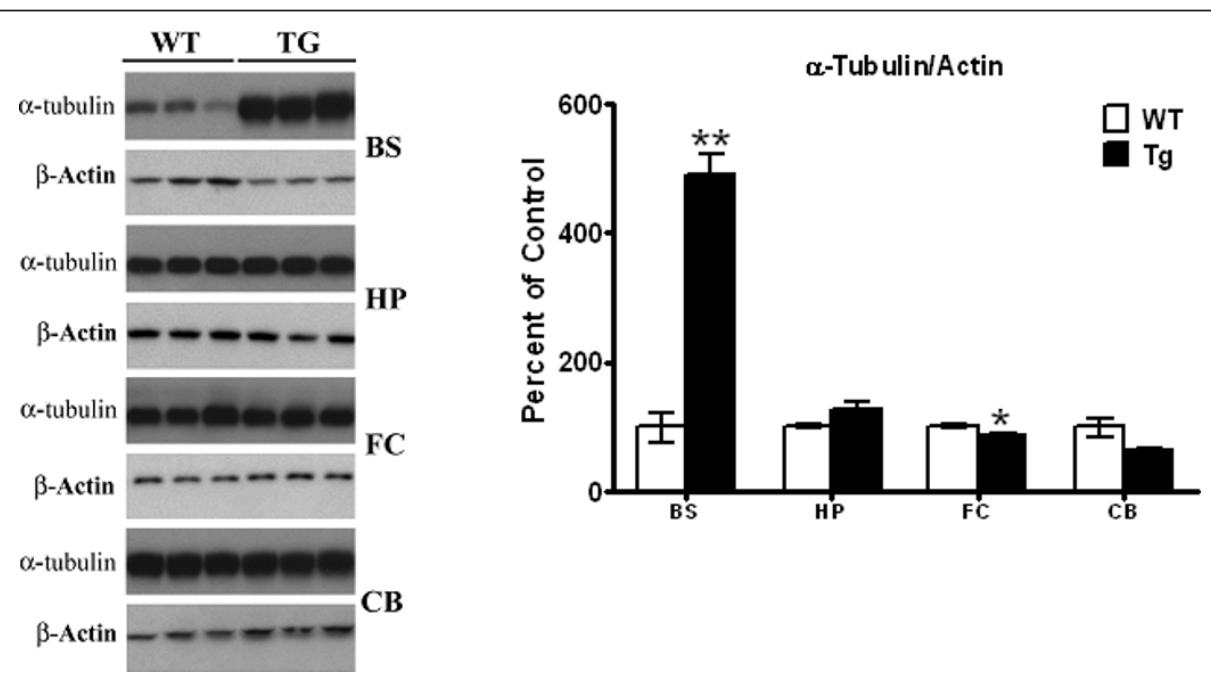

Figure 5 Analyses of soluble tubulin in different brain regions. Soluble fractions of RIPA extracts prepared from different brain regions of PDGF- $\alpha$-Syn transgenic mice and wild type controls were analyzed for $\alpha$-tubulin by Western blots as described in Methods. All values are expressed as percent change relative to changes observed in WT control animals. Results are from 3-4 animals per group; $\left.{ }^{*}, p<0.05\right]$ and [**, $p$ $<0.01$ compared to corresponding protein levels in WT animals. All blots are representative of samples. 
microtubules [MTs], leading to their destabilization, with eventual degeneration of neurons. Hyperphosphorylation at the microtubule MT binding domain [residues 244-368] of Tau is especially crucial in regulating MT stabilization, and phosphorylation at Ser262 detaches Tau from MTs, resulting in their destabilization [41]. Hyperphosphorylation at Ser396/404 promotes self assembly of Tau to form aggregates of Tau [39]. Moreover, in vitro studies using Tau peptides showed that phosphorylation of Tau at Ser262 and Ser356 modified both the negative charge and the local conformation near the phosphorylation sites, reducing the affinity of the peptides to bind to MTs [42]. Therefore, our finding of very high levels of p-Ser262 in the brain stem may explain the increased levels of soluble $\alpha$-tubulin seen in this brain region. By contrast, the other brain regions had either no [frontal cortex and cerebellum] or low increases in p-Ser262 levels [hippocampus], and, therefore, also had no changes in soluble $\alpha$-tubulin.

The pattern of tauopathy observed in this mouse model of PD closely parallels the Braak synucleinopathic staging scheme of Parkinson's disease initially proposed by Braak et al. [37]. Thus, it has been proposed that lesions initially occur in the glossopharyngeal and vagal nerves and in the anterior olfactory nucleus, progressing to the brain stem, and thereafter pursuing an ascending course of pathology [37]. Cortical involvement follows, beginning with the anteromedial temporal mesocortex, followed by the neocortex, especially the prefrontal region. The concept proposed by Braak and colleagues [37] that lower brainstem synucleinopathy represents "early PD", subsequently progressing within the human lifetime to involve the mesencephalon, suggests that the brain stem may be more severely affected than dopaminergic neurons, and this is borne out by the higher degree of tauopathy seen in the brain stem compared to the striatum in the PDGF- $\alpha$-Syn overexpressing mice. Indeed, our findings of higher levels of soluble $\alpha$-tubulin in the brain stem of the transgenic mouse as compared to the wild type also occurs in parallel with the higher levels of synucleinopathy seen in this brain region, suggesting that the brain stem is undergoing more degeneration than any other brain region tested.

Unlike our previous findings, the current study does not indicate any involvement of p-GSK-3 $\beta$ in the accumulation of $\mathrm{p}$-Tau in brain regions other than the striatum. Previously, we had found that $\alpha$-Syn could recruit and activate $\mathrm{p}-\mathrm{GSK}-3 \beta$ in a specific manner in the striatum $[32,35]$ and that such activation of p-GSK-3 $\beta$ was dependent on autoxidation of dopamine [34]. The current study suggests that in non-dopaminergic neurons, other kinases may instead become activated. Thus, our data suggest that p-ERK and p-JNK, but not pp38MAPK, become activated. To our knowledge, this is the first report of a possible involvement of p-ERK and p-JNK in the genesis of tauopathy in PD. Thus, increased levels of p-ERK are seen in brain stem, hippocampus and frontal cortex, but not in cerebellum, indicating the possible participation of this kinase in the first three brain regions mentioned. Indeed, in both PD striata and in cellular as well as animal models of PD, ongoing studies in our laboratory suggest an important and central role for $\mathrm{p}$-ERK in the pathogenesis of PD [Duka \& Sidhu, Unpublished Observations]. Since pJNK is activated in cerebellum, it is likely that the increase in p-Ser396/404 seen here proceeds through pJNK. By contrast, the increase in tauopathy seen in hippocampus is likely to occur entirely through p-ERK and not $\mathrm{p}-\mathrm{JNK}$, since $\mathrm{p}-\mathrm{JNK}$ is not activated in this region. In brain stem, however, the high levels of both p-ERK and p-JNK may together contribute to the very high levels of tauopathy seen in this region. It should be noted, however, that our results do not eliminate the possibility that other kinases may also participate in hyperphosphorylation of Tau, either in concert with, or entirely independent of, p-ERK and p-JNK.

It is now well established that overexpression of $\alpha$ Syn, through its gene duplication and triplication, is linked to idiopathic Parkinson's disease [43,9], although the mechanism[s] by which PD occurs in such populations remains elusive. The PDGF- $\alpha$-Syn overexpressing mouse model closely mimics sporadic PD [36] and our data show that at least part of the mechanism may be due to tauopathic changes in not only the striatum of these mice [33] but also in other brain regions, such as the brain stem, hippocampus, frontal cortex and cerebellum. Therapy aimed at reducing the overall tauopathic burden may be especially useful in alleviating PD.

\section{Conclusion}

In summary, our studies show that in the $\alpha$-Syn overexpressing mouse model of PD, tauopathy occurs in parallel to synucleinopathy. In brainstem, which has the highest levels of $\alpha$-Syn, the highest levels of tauopathy were also seen, which was accompanied by elevated levels of soluble $\alpha$-tubulin. In other brain regions, lower levels of $\alpha$-Syn also gave rise to lower levels of tauopathy, without any increases in $\alpha$-tubulin. The major Tau kinase, GSK-3 $\beta$, was not activated in any of the brain regions examined. Instead, activation of both p-ERK and p-JNK was variably seen implicating these kinases in the genesis of PD.

\section{Materials and methods Materials}

The antibodies used in this study are: anti-Tau MAB361 from Millipore [Temecula, CA]; anti-Tau Neurofibrillary Tangles Marker AHB0042 and anti-Tau (p-S262), Biosource Invitrogen [Carlsbad, CA]; anti- $\alpha$ - 
Syn CAT\# 610787, anti-GSK-3 $\beta$ CAT\# 612313 and anti-p-GSK-3 $\beta$ [purified mouse anti-GSK-3 $\beta$ (pY216) CAT \# 612313], from BD Transduction Labs [San Jose, CA]; anti- $\alpha$-Tubulin T6074 from Sigma-Aldrich [St. Louis, MO]; anti- $\beta$-actin SC-1616 from Santa Cruz Biotechnology, Inc. [Santa Cruz, CA]; The CP-13 and PHF-1 [recognizing Tau-Ser202 and Tau-Ser396/404, respectively] were gifts from Dr. Peter Davies [New York]; GAPDH [14C10 \#2118], p-ERK [Phospho-p44/ 42 MAPK (Erk1/2) (Thr202/Tyr204) (E10) \#9106], ERK [p44/42 MAPK (Erk1/2) (137F5) \#4695], p-p38 [Phospho-p38 MAPK (Thr180/Tyr182) (28B10) \#9216], p38 MAPK [\#9212], p-SAPK/JNK [Phospho-SAPK/JNK (Thr183/Tyr185) (G9) \#9255], and SAPK/JNK [\#9252] were all from Cell Signaling Technology [Danvers, Massachusetts].

\section{Animals}

All studies with animals were conducted under strict guidelines of the National Institutes of Research and were approved by Georgetown University Animal Care and Use Committee. Hemizygous mice overexpressing $\alpha$-Syn driven by the platelet-derived growth factor [PDGF] promoter were imported (from E. Masliah, University of California San Diego, CA). For all experiments, hemizygous PDGF- $\alpha$-Syn mice were bred with wild type (WT) mice $\left(\mathrm{C} 57 \mathrm{BL} / 6 \times \mathrm{DBA} / 2 \mathrm{~F}_{1}\right.$; B6D2F1/J) obtained from Jackson Labs to produce both WT and PDGF- $\alpha$-Syn littermates, and a breeding colony was established as described previously [36].

\section{Western Blot Analysis}

Western blot analysis was performed as described elsewhere [32,35]. Briefly, mouse brain stem, hippocampus, frontal cortex, and cerebellum from 11 month old WT and $\mathrm{Tg}$ animals were homogenized in RIPA buffer (50 $\mathrm{mM}$ Tris- $\mathrm{HCl} \mathrm{pH}$ 7.5, $150 \mathrm{mM} \mathrm{NaCl}, 1 \mathrm{mM}$ EDTA) containing $0.5 \%$ Triton $\mathrm{X}-100,0.5 \%$ sodium deoxycholate, and $0.1 \%$ SDS in the presence of protease inhibitor cocktail tablets (Complete Mini, EDTA-free; Roche Diagnostics $\mathrm{GmbH}$, Germany) and phosphatase inhibitor cocktail (Halt ${ }^{\mathrm{TM}}$ Protease Inhibitor Cocktail; Pierce). Lysates were inverted at $4^{\circ} \mathrm{C}$ for $30 \mathrm{~min}$, followed by centrifugation for $10 \mathrm{~min}$ at $15,000 \times \mathrm{g}$ and $4^{\circ} \mathrm{C}$. Supernatants were collected and protein concentrations were measured using the MBLowry assay. Samples were analyzed by Western blots on 10-20\% Tris- $\mathrm{HCl}$ Criterion gels (Bio-Rad), after blocking with $20 \mathrm{mM}$ Tris-buffered saline, $\mathrm{pH} 7.6$ containing $0.1 \%$ Tween 20 (TBST) and 5\% (wt/vol) blotting grade blocker non-fat dry milk (Bio-Rad) for 1 hour at room temperature. Western blots were developed with a wide range of specific human Tau antibodies that recognize the protein at different phosphorylation sites, including: CP13 (p-Ser202) (1:500), PHF-1 (p-Ser396/404)
(1:1000) and p-Ser262 (1:500). Total Glycogen Synthase

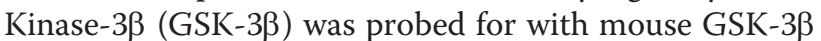
antibody (1:500) and phospho-GSK-3 $\beta$ was probed for using mouse phospho-specific (pY216) antibody (1:500). $\alpha$-Tubulin levels in RIPA-solubilized lysates was probed for with mouse $\alpha$-tubulin antibody (1:4000). To probe for $\alpha$-Syn, samples were run on $10-20 \%$ Tris $\mathrm{HCl}$ Criterion gels (Bio-Rad) and immunoblotted with mouse $\alpha$-synuclein (1:1000) antibody. All proteins were normalized to total Tau (1:1000), $\beta$-actin (1:500) or GAPDH (1:1000). After incubation for 2 hours at room temperature with HRP-conjugated secondary antibodies (1:3000, Santa Cruz), proteins were revealed by enhanced chemiluminescence (Perkin Elmer). Images were scanned by Scanner EPSON Perfection V700 Photo and then quantified using ImageJ.

\section{Immunohistochemistry}

IHC analysis of mouse brain coronal sections was performed as previously described [33], with slight modifications. Briefly, mouse brains from 11 month old control wild-type and age-matched Tg $\alpha$-Syn mutant mice were perfused with $4 \%$ PFA, and prepared in a sequential sucrose gradient, from $10 \%$ to a final $30 \%$ sucrose soak. Sections $(5 \mu \mathrm{m})$ were washed, permeabilized, and stained in the following manner. Each slice was washed 3 times in $1 \mathrm{mg} / \mathrm{ml} \mathrm{NaBr}_{2}, 1 \times \mathrm{PBS} \mathrm{pH}$ 7.4 , for $5 \mathrm{~min}$ at room temperature. Following the $\mathrm{NaBr}_{2}$ auto-fluorescence quenching treatment, each slice was washed $6 \times$, for $10 \mathrm{~min}$ in $1 \times \mathrm{PBS} \mathrm{pH} 7.4$, $1 \%$ Triton X-100 followed by blocking for $1 \mathrm{hr}$ at room temperature in $1 \times \mathrm{PBS} \mathrm{pH} 7.4,1 \%$ Triton $\mathrm{X}$ $100,10 \%$ FCS. Incubation with primary antibody occurred at $4{ }^{\circ} \mathrm{C}$, overnight in the dark, in blocking buffer using the following concentrations of antibodies: anti- $\alpha$-Syn, 1:750; PHF-1, 1:500. Following staining, each slice was washed $3 \times$ in $1 \times \mathrm{PBS}$ pH 7.4, $1 \%$ Triton X-100 at room temperature, incubated for 30 min in blocking buffer, and washed a final $3 \times$ in $1 \times$ PBS pH 7.4, 1\% Triton X-100 before incubation with appropriate secondary antibody; goat anti-mouse alexa-fluor 594, goat anti-mouse alexa-fluor 488, at the a concentration of 1:500. Following staining with secondary antibody, each slice was washed $3 \times$ in $1 \times$ PBS pH 7.4, 1\% Triton X-100 at room temperature. Stained slices were mounted to Fischer Scientific Superfrost standard microscope slides using Fluoromount-DAPI. Fluorescence images were captured using a laser scanning confocal microscope (Olympus FV300). Paired images between WT and Tg tissue for all figures were collected at the same laser power, gain, and offset settings. Post-collection processing was performed using ImageJ and applied uniformly to all paired images. 


\section{Statistical Analysis}

Results were expressed as mean \pm S.E.M. and statistically analyzed by the Student's t-test between two groups. Statistical significance was accepted at the $[p<$ 0.05] level.

\section{Acknowledgements}

We thank Peter Davies for the CP13 and PHF-1 antibodies. This study was supported in part by grants from National Institutes of Health, AG18840, AG022074 and AG5131 [E.M.] and R01AG28108, R01MH075020 and RO1NS060041 [A.S.].

\section{Author details}

'Department of Biochemistry and Molecular and Cell Biology, University of California San Diego, La Jolla, California. ${ }^{2}$ Department of Pathology, University of California San Diego, La Jolla, California.

\section{Authors' contributions}

TK performed majority of the experiments, collected data and performed statistical analyses; JC performed the IHC studies, conducted the interpretation and assisted in preparation of manuscript; $\mathrm{TH}$ performed the tubulin studies, analyzed data, statistics and helped in interpretation, we well as writing of the manuscript; AWO conducted the dissections of various brain regions and assisted in interpretation of results and writing of the manuscript; EM provided the transgenic mice and assisted in interpretation of data; AS conceived of the study, and participated in its design and coordination. All authors read and approved the final manuscript.

\section{Competing interests}

The authors declare that they have no competing interests.

Received: 4 May 2011 Accepted: 3 August 2011

Published: 3 August 2011

\section{References}

1. Sidhu A, Wersinger C, Moussa CE, Vernier P: The role of alpha-synuclein in both neuroprotection and neurodegeneration. Ann N Y Acad Sci 2004 1035:250-270

2. Singleton $A B$, Farrer $M$, Johnson J, Singleton $A$, Hague S, Kachergus J, Hulihan M, Peuralinna T, Dutra A, Nussbaum R, Lincoln S, Crawley A Hanson M, Maraganore D, Adler C, Cookson MR, Muenter M, Baptista M, Miller D, Blancato J, Hardy J, Gwinn-Hardy K: a-Synuclein locus triplication causes Parkinson's disease. Science 2003, 302:841-846.

3. Chartier-Harlin MC, Kachergus J, Roumier C, Mouroux V, Douay X, Lincoln S, Levecque C, Larvor L, Andrieux J, Hulihan M, Waucquier N, Defebvre L, Amouyel P, Farrer M, Destée A: a-Synuclein locus duplication as a cause of familial Parkinson's disease. Lancet 2004, 364:1167-1169.

4. Ibáñez $P$, Bonnet AM, Débarges B, Lohmann E, Tison F, Pollak P, Agid $Y$, Dürr A, Brice A: Causal relation between a-synuclein gene duplication and familial Parkinson's disease. Lancet 2004, 364:1169-1171.

5. Nishioka K, Hayashi S, Farrer MJ, Singleton AB, Yoshino H, Imai H, Kitami T, Sato K, Kuroda R, Tomiyama H, Mizoguchi K, Murata M, Toda T, Imoto I, Inazawa J, Mizuno Y, Hattori N: Clinical heterogeneity of a-synuclein gene duplication in Parkinson's disease. Ann Neurol 2006, 59:298-309.

6. Fuchs J, Nilsson C, Kachergus J, Munz M, Larsson EM, Schüle B, Langston JW, Middleton FA, Ross OA, Hulihan M, Gasser T, Farrer MJ: Phenotypic variation in a large Swedish pedigree due to SNCA duplication and triplication. Neurology 2007, 68:916-922.

7. Polymeropoulos MH, Lavedan C, Leroy E, Ide SE, Dehejia A, Dutra A, Pike B, Root H, Rubenstein J, Boyer R, Stenroos ES, Chandrasekharapa S, Athanassiadou A, Papapetropoulos T, Johnson WG, Lazzarini AM, Duvoisin RC, Di lorio G, Golbe Ll: Mutation in the alpha-synuclein gene identified in families with Parkinson's disease. Science 1997, 276:2045-2047.

8. Kruger R, Kuhn W, Muller T, Woitalla D, Graeber M, Kosel S, Przuntek H, Eplen JT, Schols L, Riess O: Ala30Pro mutation in the gene encoding alpha-synuclein in Parkinson's disease. Nat Genet 1998, 18:106-108.
9. Spillantini MG, Crowther RA, Jakes R, Hasegawa M, Goedert M: asynuclein in filamentous inclusions of Lewy bodies from Parkinson's disease and dementia with Lewy bodies. Proc Natl Acad Sci USA 1998, 95:6469-6473.

10. Masliah E, Rockenstein E, Veinbergs J, Mallory M, Hashimoto M, Takeda A, Sagara Y, Sisk A, Mucke L: Dopaminergic loss and inclusion body formation in a-synuclein mice: implications for neurodegenerative disorders. Science 2000, 287:1265-1269.

11. El-Agnaf OMA, Jakes R, Curran MD, Wallace A: Effects of the mutations Ala30 to Pro and Ala53 to Thr on the physical and morphological properties of a-synuclein protein implicated in Parkinson's disease. FEBS Letts 1998, 440:67-70.

12. Gosavi N, Lee H J, Lee JS, Patel S, Lee SJ: Golgi fragmentation occurs in the cells with prefibrillar a-synuclein aggregates and precedes the formation of fibrillar inclusions. J Biol Chem 2002, 277:48984-48992.

13. Yamazaki M, Arai Y, Baba M, Iwatsubo T, Mori O, Katayama Y, Oyanagi K Alpha-synuclein inclusions in amygdala in the brains of patients with the parkinsonism-dementia complex of Guam. J Neuropathol Exp Neurol 2000, 59:585-591.

14. Arai Y, Yamazaki M, Mori O, Muramatsu H, Asano G, Katayama Y: Alpha synuclein-positive structures in cases with sporadic Alzheimer's disease: morphology and its relationship to tau aggregation. Brain Research 2001, 888:287-296.

15. Duda JE, Giasson BI, Mabon ME, Miller DC, Golbe LI, Lee VM, Trojanowski JQ: Concurrence of alpha-synuclein and tau brain pathology in the Contursi kindred. Acta Neuropathol 2002, 104:7-11.

16. Forman MS, Schmidt ML, Kasturi S, Perl DP, Lee VM, Trojanowski JQ: Tau and alpha-synuclein pathology in amygdala of Parkinsonism-dementia complex patients of Guam. Am J Pathol 2002, 160:1725-1731.

17. Ishizawa T, Mattila P, Davies P, Wang D, Dickson DW: Colocalization of tau and alpha-synuclein epitopes in Lewy bodies. J Neuropathol Exp Neurol 2003, 62:389-397.

18. Tsuboi Y, Wszolek ZK, Graff-Radford NR, Cookson N, Dickson DW: Tau pathology in the olfactory bulb correlates with Braak stage, Lewy body pathology and apolipoprotein epsilon4. Neuropathol Apl Neurobiol 2003, 29:503-510.

19. Kotzbauer PT, Giasson Bl, Kravitz AV, Golbe LI, Mark MH, Trojanowski JQ, Lee VM: Fibrillization of alpha-synuclein and tau in familial Parkinson's disease caused by the A53T alpha-synuclein mutation. Exp Neurol 2004, 187:279-288.

20. Yamaguchi K, Cochran EJ, Murrell JR, Polymeropoulos MH, Shannon KM, Crowther RA, Goedert M, Ghetti B: Abundant neuritic inclusions and microvacuolar changes in a case of diffuse Lewy body disease with the A53T mutation in the alpha-synuclein gene. Acta Neuropathol 2005, 110:298-305.

21. Hamilton RL: Lewy bodies in Alzheimer's disease: a neuropathological review of 145 cases using alpha-synuclein immunohistochemistry. Brain Pathol 2000, 10:378-384.

22. Szpak GM, Lewandowska E, Lechowicz W, Bertrand E, Wierzba-Bobrowicz T, Gwiazda E, Pasennik E, Kosno-Kruszewska E, Lipczynska-Lojkowska W, Bochynska A, Fiszer U: Lewy body variant of Alzheimer's disease and Alzheimer's disease: a comparative immunohistochemical study. Folia Neuropathol 2001, 39:63-71.

23. Jellinger KA: Lewy body-related alpha-synucleinopathy in the aged human brain. J Neural Transm 2004, 111:1219-1235.

24. Nemes Z, Devreese B, Steinert PM, Van Beeumen J, Fesus L: Cross-linking of ubiquitin, HSP27, parkin, and alpha-synuclein by gamma-glutamylepsilon-lysine bonds in Alzheimer's neurofibrillary tangles. FASEB J 2004, 18:1135-1137.

25. Griffin WS, Liu L, Li Y, Mrak RE, Barger SW: Interleukin-1 mediates Alzheimer and Lewy body pathologies. J Neuroinflammation 2006, 3:5-9.

26. Lei P, Ayton S, Finkelstein DI, Adlard PA, Masters CL, Bush Al: Tau protein: Relevance to Parkinson's disease. Int J Biochem Cell Biol 2010, 42:1775-1778.

27. Lipa CF, Fujiwara H, Mann DM, Giasson B, Baba M, Schmidt ML, Nee LE, O'Connell B, Pollen DA, St George-Hyslop P, Ghetti B, Nochlin D, Bird TD, Cairns NJ, Lee VM, Iwatsubo T, Trojanowski JQ: Lewy bodies contain altered alpha-synuclein in brains of many familial Alzheimer's disease patients with mutations in presenilin and amyloid precursor protein genes. Am J Pathol 1998, 153:1365-1370. 
28. Iseki E, Marui W, Kosaka K, Ueda K: Frequent coexistence of Lewy bodies and neurofibrillary tangles in the same neurons of patients with diffuse Lewy body disease. Neurosci Lett 1999, 265:9-12.

29. Duka T, Rusanak M, Drolet R, Duka V, Wersinger C, Goudreau JL, Sidhu A: Alpha-synuclein induces hyperphosphorylation of Tau in the MPTP model of Parkinsonism. FASEB J 2006, 20:2302-2312.

30. Duka T, Sidhu A: The Neurotoxin MP induces hyperphosphorylation of Tau in the presence of alpha-synuclein in SHSY-5Y neuroblastoma cells. Neurotox Res 2006, 10:1-10.

31. Kozikowski AP, Gaisina IN, Petukhov PA, Sridhar J, King LT, Blond SY, Duka T, Rusnak M, Sidhu A: Highly potent and specific GSK-3beta inhibitors that block tau phosphorylation and decrease alpha-synuclein protein expression in a cellular model of Parkinson's disease. ChemMedChem 2006, 1:256-266.

32. Duka T, Duka V, Joyce JN, Sidhu A: Alpha-Synuclein contributes to GSK3beta-catalyzed Tau phosphorylation in Parkinson's disease models. FASEB J 2009, 23:2820-2830.

33. Haggerty T, Credle J, Rodriguez O, Wills J, Oaks AW, Masliah E, Sidhu A: Hyperphosphorylated Tau in an a-synuclein overexpressing transgenic model of Parkinson's disease. Eur J Neurosci 2011, 33:1598-610.

34. Wills J, Credle J, Haggerty T, Lee J-H, Oaks AW, Sidhu A: Tauopathic changes in the striatum of A53T a-synuclein mutant mouse model of Parkinson's disease. PlosOne 2011, 6:e17953.

35. Wills J, Jones J, Haggerty T, Valeriy D, Joyce J, Sidhu A: Elevated tauopathy and alpha-synuclein pathology in postmortem Parkinson's disease brain with and without dementia. Exp Neurol 2010, 225:210-218.

36. Rockenstein $E$, Mallory M, Hashimoto M, Song D, Shults CW, Lang I, Masliah E: Differential neuropathological alterations in transgenic mice expressing alpha-synuclein from the platelet-derived growth factor and Thy-1 promoters. J Neurosci Res 2002, 68:568-578.

37. Braak H, Del Tredici K, Rüb U, de Vos RA, Jansen Steur EN, Braak E: Staging of brain pathology related to sporadic Parkinson's disease. Neurobiol Aging 2003, 24:197-211.

38. Hanger DP, Anderton BH, Noble W: Tau phosphorylation: the therapeutic challenge for neurodegenerative disease. Trends in Molec Med 2009, 15:112-119.

39. Alonso AC, Li B, Grundke-lqbal I, lqbal K: Mechanism of tau-induced neurodegeneration in Alzheimer disease and related tauopathies. Curr Alzheimer Res 2008, 5:375-84.

40. Muntané G, Dalfó E, Martinez A, Ferrer I: Phosphorylation of Tau and alpha-synuclein in synaptic-enriched fractions of the frontal cortex in Alzheimer's disease, and in Parkinson's disease and related alphasynucleinopathies. Neuroscience 2008, 152:913-923.

41. Buée L, Bussière T, Buée-Scherrer V, Delacourte A, Hof PR: Tau protein isoforms, phosphorylation and role in neurodegenerative disorders. Brain Res Brain Res Rev 2000, 33:95-130.

42. Du JT, Li YM, Ma QF, Qiang W, Zhao YF, Abe H, Kanazawa K, Qin XR, Aoyagi R, Ishizuka Y, Nemoto T, Nakanishi H: Synthesis and conformational properties of phosphopeptides related to the human tau protein. Regul Pept 2005, 130:48-56.

43. Forno LS: Neuropathology of Parkinson's disease. J Neuropathol Exp Neurol 1996, 55:259-272.

doi:10.1186/1471-2202-12-79

Cite this article as: Kaul et al:: Region-specific tauopathy and

synucleinopathy in brain of the alpha-synuclein overexpressing mouse model of Parkinson's disease. BMC Neuroscience 2011 12:79.

\section{Submit your next manuscript to BioMed Central and take full advantage of:}

- Convenient online submission

- Thorough peer review

- No space constraints or color figure charges

- Immediate publication on acceptance

- Inclusion in PubMed, CAS, Scopus and Google Scholar

- Research which is freely available for redistribution

Submit your manuscript at www.biomedcentral.com/submit
C Biomed Central 